\title{
Review
}

\section{Leptin receptor action and mechanisms of leptin resistance}

\author{
H. Münzberg, M. Björnholm, S. H. Bates and M. G. Myers Jr* \\ Division of Metabolism, Endocrinology and Diabetes, Departments of Internal Medicine and Molecular \\ and Physiology, University of Michigan Medical School, 1150 W. Medical Center Dr., 4301 MSRB 3, Box 0638, \\ Ann Arbor, Michigan 48109-0638 (USA), Fax: +1 734936 6684, e-mail: mgmyers@umich.edu
}

Received 30 September 2004; received after revision 12 November 2004; accepted 23 November 2004

\begin{abstract}
The adipose tissue-derived hormone leptin regulates energy balance and neuroendocrine function. Resistance to the appetite-suppressing effects of leptin is associated with common forms of obesity. Here, we review the mechanisms by which leptin activates intracellular signals and the roles that these signals play in
\end{abstract}

leptin action in vivo. Furthermore, we discuss potential mechanisms of leptin resistance, specifically focusing on data regarding the neuroanatomical locus of leptin resistance and potential mechanisms by which expression of the suppressor of cytokine signaling-3 may impair leptin action.

Key words. Leptin; obesity; SOCS3; signaling; arcuate nucleus; hypothalamus.

\section{Leptin}

The adipose tissue-derived hormone leptin is produced in proportion to fat stores. Circulating leptin serves to communicate the state of body energy repletion to the central nervous system (CNS) in order to suppress food intake and permit energy expenditure (fig. 1) [1-3]. Leptin fits the criteria for a feedback signal from body energy stores to the brain as defined by Kennedy [4] in 1953: leptin levels drop during starvation, when fat depots are depleted to support the organism's basic energy needs, and leptin levels rise during refeeding where fat depots are replenished. Furthermore, many of the physiological adaptations triggered by prolonged fasting can be prevented by exogenously administered leptin during the fast, which falsely signals to the brain that energy stores are replete $[3,5,6]$. Adequate leptin levels permit energy expenditure in the processes of reproduction and growth and similarly regulate the autonomic nervous system, other elements of the endocrine system and the immune system [3, $5,6]$. Conversely, lack of leptin signaling due to mutation

\footnotetext{
* Corresponding author.
}

of leptin (e.g. $o b / o b$ mice) or the leptin receptor (LR) (e.g. $d b / d b$ mice) in rodents and humans results in increased food intake in combination with a reduced energy expenditure phenotype reminiscent of the neuroendocrine starvation response (including hypothyroidism, decreased growth, infertility and decreased immune function) in spite of their obesity $[1,2,7,8]$.

\section{LRs and sites of leptin action}

There are multiple LR isoforms, all of which are products of a single lepr gene $[9,10]$. The lepr gene contains 17 common exons and several alternatively spliced 3 '-exons. In mice, the six distinct LR isoforms that have been identified are designated LRa-LRf. In all species, LR isoforms can be divided into three classes: secreted, short and long. The secreted forms are either products of alternatively spliced messenger RNA (mRNA) species (e.g. murine LRe, which contains only the first 14 exons of lepr) or proteolytic cleaveage products of membranebound forms of LR. These secreted forms contain only extracellular domains that bind circulating leptin, perhaps regulating the concentration of free leptin [11]. 


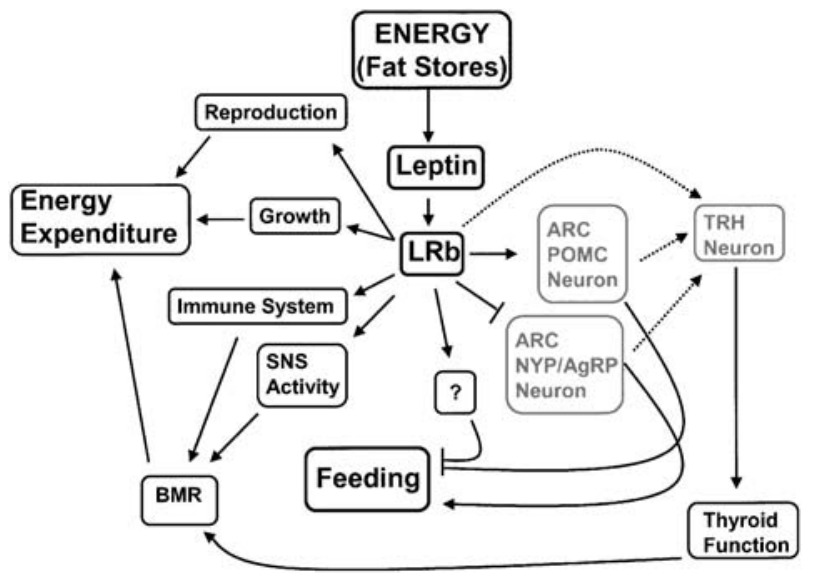

Figure 1. Regulation of feeding and neuroendocrine function by leptin. Leptin is secreted from adipocytes as a signal of energy (fat) stores. Circulating leptin activates the long form leptin receptor $(\mathrm{LRb})$ on target cells to regulate energy intake and energy expenditure. Within the brain, two distinct sets of neurons in the arcuate nucleus of the hypothalamus (ARC) are known to be regulated by leptin. The ARC POMC-expressing neuron (an anorexogenic/ appetite-suppressing neuron) is activated by leptin, while the Arc $\mathrm{NPY} / \mathrm{AgRP}$ neuron (an orexigenic/appetite-stimulating neuron) is inhibited by leptin; the combination of leptin effects on these and other unidentified neurons (labeled '?') mediates the anorectic actions of leptin. The ARC POMC and NPY/AgRP neuron as well as some direct actions of leptin stimulate the TRH neuron to enable the full elaboration of thyroid hormone to permit energy expenditure by modulating the basal metabolic rate (BMR). Leptin also permits energy expenditure by increasing the activity of the sympathetic nervous system (SNS), and stimulating the growth and reproductive axes. Additionally, leptin enables the proliferation of cells required to mount an effective immune response. Thus, leptin sufficiency acts to permit energy expenditure by systems throughout the body, as well as to modulate appetite.

Short form LRs (LRa, LRc, LRd and LRf in mice) and the long form LR (LRb in mice) contain exons 1-17 of lepr and therefore have identical extracellular and transmembrane domains as well as the same first 29 intracellular amino acids, but diverge in sequence thereafter due to the alternative splicing of $3^{\prime}$ exons. Shortform LRs contain exons 1-17 and truncate 3-11 amino acids after the splice junction. LRc-, LRd- and LRfspecific sequences are not well conserved among species. However, LRa (the most abundantly expressed isoform) is reasonably well conserved, as is LRb, which has an intracellular domain of approximately 300 residues $[9,10]$.

$\mathrm{LRb}$ is crucial for leptin action. Indeed, the originally described $d b / d b$ mice lack LRb (but not other LR forms) as a consequence of a mutation that causes mis-splicing of the LRb mRNA; these mice display a phenotype that is indistinguishable from that of $d b^{3 J} / d b^{3 J}$ mice (which are deficient in all LR isoforms) and of leptin-deficient $o b / o b$ animals [3]. The function of short-form LRs is less clear, although proposed roles include the transport of leptin across the blood-brain barrier and the production of circulating LR extracellular domain to complex with leptin.

Many of the effects of leptin are attributed to effects in the CNS, particularly in the basomedial hypothalamus, a site of high LRb mRNA expression [12-15]. Here, leptin acts on neurons that regulate levels of circulating hormones (e.g. thyroid hormone, sex steroids and growth hormone) $[12,16,17]$. Leptin action on these hypothalamic neurons also regulates the activity of the autonomic nervous system, although direct effects of leptin on LRb-containing neurons in the brainstem and elsewhere probably also have an important role [18]. The effects of leptin on the immune system appear to result from direct action on $\mathrm{T}$ cells that contain $\mathrm{LRb}[6]$. Leptin might also regulate glucose homeostasis independently of effects on adiposity; leptin regulates glycemia at least partly via the CNS, but it might also directly regulate pancreatic $\beta$ cells and insulin-sensitive tissues [19-22].

\section{Leptin regulation of neural networks and neurophysiology}

$\mathrm{LRb}$ is present in several tissues, with the highest levels in neurons of several nuclei of the hypothalamus, including the arcuate (ARC), dorsomedial (DMH), ventromedial $(\mathrm{VMH})$ and premammillary nuclei [12-14]. Other sites within the brain that have been shown to express $\mathrm{LRb}$ by in situ hybridization histochemistry for LRb mRNA or by detection of leptin-mediated signaling include the brainstem [nucleus of the solitary tract (NTS) and dorsal motor nucleus of the vagus (DMX)], periaqueductal gray matter and hippocampus. LRb mRNA is highly expressed in the ARC, and LRb signaling is most readily detectable here, as well; $\mathrm{LRb}$ is found in at least two distinct populations of ARC neurons. One population synthesizes neuropeptide Y (NPY) and agouti-related peptide (AgRP), and the other synthesizes pro-opiomelanocortin (POMC) [12,15]. POMC is processed to produce $\alpha$-melanocyte-stimulating-hormone $(\alpha \mathrm{MSH})$ in LRb/POMC neurons, which signals anorexia (decreased appetite) by activating the melanocortin-4 receptor (MC4R) and to a lesser extent the melanocortin-3 receptor (MC3R) [23-28]. LRb stimulates the synthesis of POMC and activates/depolarizes $\mathrm{LRb} / \mathrm{POMC}$ neurons $[15,29]$. NPY is an orexigenic (appetite-stimulating) hormone that also suppresses the central LRb-mediated growth and reproductive axes. $\mathrm{AgRP}$ is an antagonist of $\alpha \mathrm{MSH} / \mathrm{MC} 4 \mathrm{R}$ signaling as well as an inhibitor (inverse agonist) of endogenous MC4R activity. Leptin acts via LRb to inhibit NPY/ AgRP neurons and suppress expression of these neuropeptides $[15,29]$. Thus, LRb signaling stimulates the production of anorectic neuropeptides and suppresses 
levels of orexigenic peptides. Conversely, a decrease or deficiency in leptin activity (e.g. during starvation and in $o b / o b$ and $d b / d b$ mice) stimulates appetite by suppressing synthesis of anorectic neuropeptides (e.g. POMC) and increasing expression of orexigenic peptides (e.g. $\mathrm{NPY}$ and AgRP). In the ARC, neurons that express LRb mRNA plus NPY/AgRP and/or POMC also regulate energy expenditure and other elements of neuroendocrine function.

Although the detailed mechanisms by which the ARC NPY/AgRP and POMC neurons function continue to emerge at an astounding rate, numerous questions remain regarding the contributions of each circuit to the regulation of feeding in general and in response to leptin under physiologic conditions. In spite of the dramatic orexigenic effect of NPY and AgRP administration or of substances that activate the NPY/AgRP neuron (e.g. ghrelin) [15, 29-31], genetic ablation of AgRP or NPY minimally impacts ad libitum feeding and body weight $[31,32]$. While the minimal phenotype of NPY or AgRP deletion on body weight has led some to suggest a minimal contribution of these neuropeptides to energy homeostasis, it is likely that they substantially affect the response to caloric deprivation, e.g. in fasting or in low-leptin states, as shown for $o b / o b$ and diabetic animals [33, 34]. It is also likely that additional strong counter-regulatory mechanisms act to prevent underfeeding and may compensate for the lack of these neuropeptides.

Although ablation of POMC or central melanocortin receptors results in severe obesity [24,35], deletion of $\mathrm{LRb}$ from POMC neurons results in only modest weight gain [36]. Thus, while melanocortins generally effect a powerful anorectic signal, they may not constitute the majority of the leptin-mediated anorectic signal, which may be mediated by other, potentially unrecognized, populations of LRb-expressing neurons. Indeed, histochemically leptin-sensitive POMC neurons represent only a small subpopulation of the total ARC POMC neurons; conversely, POMC neurons represent only a small fraction of the total leptin-regulated neurons within the ARC [37], suggesting the presence of significant leptinindependent melanocortin signals and melanocortin-independent leptin function. The functional and neurochemical properties of LRb-regulated neurons in the $\mathrm{DMH}, \mathrm{VMH}$ and elsewhere (including the brainstem) are poorly characterized.

\section{LR signaling}

LRb belongs to the interleukin (IL)-6 receptor family of class 1 cytokine receptors, which contain an extracellular ligand-binding domain a single transmembrane domain, and a cytoplasmic signaling domain $[9,38]$. Like other cytokine receptors, LRb does not contain intrinsic enzy- matic activity, but instead signals via a non-covalently associated tyrosine kinase of the Jak kinase family (Jak2 in the case of LRb) [39-41]. Unliganded LRb exists as a pre-formed homodimer; leptin binding alters the conformation of the $\mathrm{LRb}$ dimer, enabling transphosphorylation and activation of the intracellular LRb-associated Jak2 molecules $[9,42,43]$. The activated Jak2 molecule then phosphorylates other tyrosine residues within the LRb/Jak2 complex to mediate downstream signaling $[44,45]$.

Signaling by cytokine receptors requires a proline-rich 'Box 1' motif critical for Jak kinase interaction and activation; additional less-conserved sequences $\mathrm{COOH}$ terminal to Box 1 (sometimes referred to as 'Box 2') are also important for Jak kinase interactions and likely function in Jak kinase isoform selectivity [38, 39, 41, 46]. In the case of LRb, intracellular residues 31-36 (i.e. immediately downstream of the alternative splice junction following amino acid 29) compose Box 2 [41, 46], which is absent from all described short LR isoforms- consistent with the inability of these molecules to mediate leptin action in $d b / d b$ animals [9, 41, 44].

Tyrosine kinase-dependent signaling generally proceeds via the phosphotyrosine-dependent recruitment of signaling proteins that contain specialized phosphotyrosine binding domains (e.g. SH2 domains) [47]. Each SH2 domain isoform recognizes phosphotyrosine in a specific amino acid context. Thus, while tyrosine phosphorylation acts as a molecular switch to recruit $\mathrm{SH} 2$-containing proteins, each tyrosine phosphorylation site recruits only specific $\mathrm{SH} 2$ isoforms, since they recognize the surrounding amino acids as well as the phosphotyrosine residue. For instance, the $\mathrm{SH} 2$ domain of the latent transcription factor, STAT3, is recruited to phosphotyrosine in the context of a Y(P)XXQ motif $[48,49]$.

Understanding signaling by the LRb/Jak2 complex thus requires defining the tyrosine phosphorylation sites on $\mathrm{LRb}$ and Jak2 and the $\mathrm{SH} 2$ proteins that they recruit. There are three conserved residues on the intracellular domain of $\mathrm{LRb}-\mathrm{Tyr}_{985}, \mathrm{Tyr}_{1077}$, and $\mathrm{Tyr}_{1138}[9,44,45]$. $\mathrm{Tyr}_{985}$ and $\mathrm{Tyr}_{1138}$ are phosphorylated upon leptin binding, while $\mathrm{Tyr}_{1077}$ is not phosphorylated and does not contribute to leptin signaling [45].

There are thus three primary intracellular signaling pathways that emanate from $\mathrm{LRb}$ (fig. 2): those originating directly from Jak2 tyrosine phosphorylation sites, from $\mathrm{Tyr}_{985}$ of LRb and from $\mathrm{Tyr}_{1138}$ of LRb. The phosphorylation of $\mathrm{Tyr}_{985}$ creates a binding site for the $\mathrm{COOH}$-terminal SH2 domain of the tyrosine phosphatase, SHP-2, leading to the activation of the canonical p21ras $\rho \rightarrow$ ERK signaling pathway in cultured cells. While $\mathrm{Tyr}_{985}$ thus mediates the majority of ERK stimulation during LRb signaling in cultured cells, a portion of leptin-stimulated ERK activation is regulated independently of LRb phosphorylationpresumably via tyrosine phosphorylation sites on Jak2 $[41,45,50]$. 


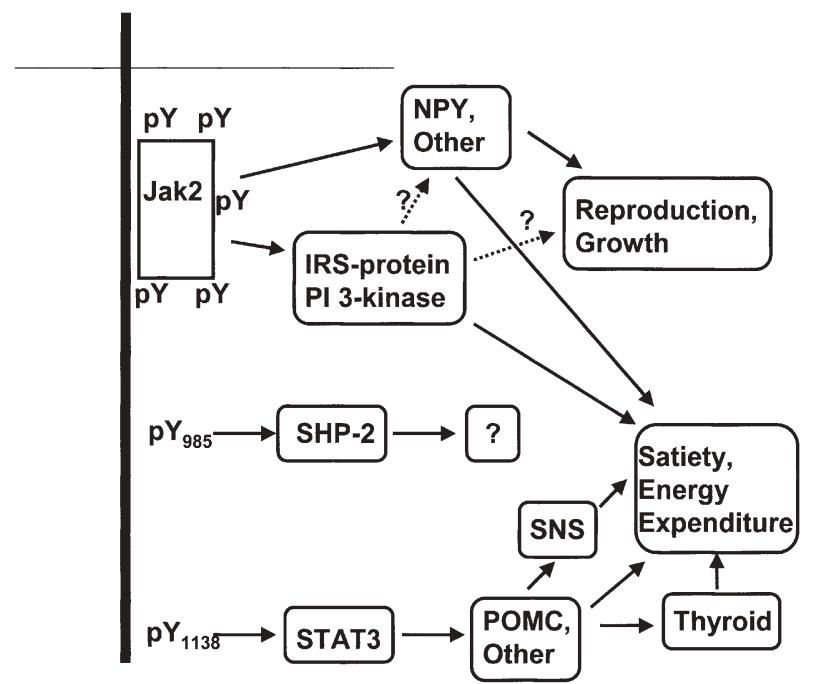

Figure 2. Signaling by LRb. Leptin binding to LRb activates the LRb-associated Jak2 tyrosine kinase, in turn promoting the autophosphorylation of tyrosine residues on Jak2 and the phosphorylation of $\mathrm{Tyr}_{985}$ and $\mathrm{Tyr}_{1138}$ on the intracellular tail of $\mathrm{LRb}$. While the physiologic function of $\mathrm{Tyr}_{985}$ and its binding partner (SHP-2) in signaling is not clear, the recruitment of the transcription factor, STAT3, by phosphorylated $\mathrm{Tyr}_{1138}$ mediates the transcriptional regulation of a variety of critical satiety signals in vivo (e.g. POMC). STAT3-dependent mechanisms mediate the actions of LRb on SNS and thyroid function to control energy expenditure as well. Importantly, phosphorylation sites on Jak2, independently of LRb tyrosine phosphorylation sites, activate the IRS-protein $\rightarrow$ PI 3-kinase pathway. This and perhaps other Jak2-dependent pathways are the primary leptin-stimulated regulators of NPY neuronal function, reproduction and growth, as well as contributing to satiety and energy expenditure.

Phosphorylation of $\mathrm{Tyr}_{1138}$ recruits STAT3 to the LRb/Jak2 complex, resulting in the tyrosine phosphorylation and subsequent nuclear translocation of STAT3 to mediate transcriptional regulation [44, 45]. Among other genes, STAT3 mediates the transcription of the SH2 domaincontaining feedback inhibitor, suppressor of cytokine signaling (SOCS)-3 [45, 51]. SOCS3 binds to Tyr $_{985}$ of $\mathrm{LRb}$ to mediate inhibition of $\mathrm{LRb} \rightarrow$ STAT3 signaling [52]; SOCS3 also binds to a separate site on Jak2 itself [53, 54]. The relative importance of these two binding sites and the contribution of the $\mathrm{Tyr}_{1138} \rightarrow$ STAT3 pathway to the generation of SOCS3 levels in LRb-expressing tissues in vivo are not known at this time.

Jak2 tyrosine phosphorylation during LRb stimulation mediates some signals independently of tyrosine phosphorylation sites on LRb (e.g. a portion of ERK activation) [45]. The individual tyrosine phosphorylation sites on Jak2 are beginning to be enumerated [55-59], but many more remain to be identified, and the binding partners and signals mediated by many sites are not known, limiting our understanding of the mechanisms by which Jak2-dependent signals are mediated. LRb stimulation mediates the tyrosine phosphorylation of insulin receptor substrate (IRS) proteins and activation of the phosphoinositide (PI) 3'-kinase pathway [60], presumably via tyrosine phosphorylation sites on Jak2. Although the exact mechanisms by which Jak2 mediates activation of the IRS-protein $\rightarrow$ PI 3-kinase pathway is not understood, it is clear that this pathway represents an important component of leptin action in vivo as well as an important area of crosstalk with insulin signaling [60-64].

\section{LRb signaling in the regulation of physiology}

Thus far, two LRb signaling pathways have been implicated in leptin action: STAT3 (see below), and the IRS protein $\rightarrow$ PI 3'-kinase pathway. First described as insulin receptor substrates, the IRS proteins (IRS-1-4), are members of a class of intracellular signaling molecules termed docking proteins that are phosphorylated by several tyrosine kinases (e.g. insulin receptor and some cytokine receptors) [65]. Docking proteins, including the IRS, are devoid of enzymatic activity, but are phosphorylated on multiple tyrosine residues to mediate $\mathrm{SH} 2$-protein recruitment and downstream signaling. Although IRS proteins contain tyrosine phosphorylation sites in numerous motifs that recruit several different SH2 proteins, most sites lie in YMXM motifs that bind and activate PI 3'-kinase.

The first, albeit indirect, evidence for a potential role of the IRS protein $\rightarrow$ PI $3^{\prime}$-kinase pathway in leptin action came from the phenotype of the IRS-2 null (IRS-2-开) mouse $[66,67]$. In addition to other defects, IRS-2 $2^{--}$animals display increased feeding and decreased metabolic rate in the presence of increased adiposity and circulating leptin, suggesting functional leptin resistance (although it is not as severe as in $d b / d b$ animals) [67]. No such phenotype has been noted in animals null for any of the other three IRS proteins [68], suggesting a specialized role for IRS-2 in anorectic signaling.

Blockade of PI 3'-kinase activity abrogates leptinmediated hyperpolarization/inhibition of (presumably) LRb/NPY/AgRP hypothalamic neurons $[69,70]$. Furthermore, leptin stimulates IRS-2-associated PI 3'kinase activity in the hypothalamus, and pharmacological blockade of PI 3'-kinase activity in the hypothalamus blocks the anorectic effect of leptin in vivo [60] PI 3 '-kinase activity is also required for leptin-regulated sympathetic nervous system function [71]. It will be interesting to determine both the role of this pathway in leptin resistance and the neuropeptide phenotype of the neuronal population(s) in which PI 3'-kinase activity is required for the anorectic actions of leptin and insulin, as well as the role of PI 3'-kinase in other leptin functions (e.g. neuroendocrine and immune regulation). 


\section{LRb signaling via STAT3 mediates a subset of leptin actions}

We have directly addressed the contribution of the LRbSTAT3 pathway to physiology by studying homologously targeted 'knock-in' mice in which LRb is replaced by a mutant molecule $\left(\mathrm{LRb}^{\mathrm{S} 1138}\right)$ that contains a substitution mutation of $\mathrm{Tyr}_{1138}$ (the STAT3 binding site) [72]. Although $\mathrm{LRb}^{\mathrm{S1} 138}$ fails to mediate activation of STAT3 during leptin signaling, this mutant regulates all other $\mathrm{LRb}$ signaling pathways normally. The use of the 'knockin' approach ensures that the expression pattern and levels of $\mathrm{LRb}^{\mathrm{S} 1138}$ mirror that of wild-type LRb. This system has several advantages over other approaches such as the ablation of STAT3 using neural-specific expression of Cre recombinase in combination with conditional alleles of STAT3 [73], as STAT3 is required for signaling by numerous receptors (other than LRb) critical to brain function, and the approach of STAT3 ablation cannot be specific for LRb action even if it were specific for $\mathrm{LRb}$ neurons.

Similar to $d b / d b$ animals, mice homozygous for $\mathrm{LRb}^{\mathrm{S1138}}$ expression $(s / s)$ display hyperphagia and decreased energy expenditure, resulting in profound obesity that is associated with increased serum leptin levels. The high circulating leptin levels in $s / s$ animals not only correlate with increased adipose mass in these mice, but also indicate resistance to the energy homeostatic effects of leptin [72]. Feeding is similarly high in $s / s$ and $d b / d b$ mice, and energy expenditure is decreased identically in these two mouse strains [74]. There is evidence that leptin regulates thyroid function via both direct and indirect pathways $[17,75-78]$; each of these appear to be STAT3 dependent, as the thyroid function of $s / s$ and $d b / d b$ mice is similarly depressed [74]. Similarly, energy expenditure mediated by the activity of the sympathetic nervous system is similarly depressed in $s / s$ and $d b / d b$ mice by the assay of uncoupling protein-1 expression in brown adipose tissue [74].

Important differences exist between the phenotypes of $s / s$ mice (missing only the LRb-STAT3 signal) and $d b / d b$ mice (devoid of all leptin signals), however [72]. Whereas $d b / d b$ animals are floridly diabetic, infertile and demonstrate decreased linear growth, $s / s$ mice demonstrate greatly improved glucose tolerance compared to $d b / d b$ mice, retain relatively normal gonad function and demonstrate increased linear growth compared with wild-type animals.

Analysis of hypothalamic neuropeptide expression reveals that, similar to $d b / d b$ mice, $s / s$ mice have decreased POMC and increased AgRP mRNA levels in the hypothalamus [72]. By contrast, whereas $d b / d b$ animals display dramatic induction of hypothalamic NPY mRNA, levels of NPY message are near normal in $s / s$ animals. These data suggest that LRb-STAT3 signaling is a crucial regulator of hypothalamic melanocortin action, and that dysregulated melanocortin signaling (as opposed to alterations in NPY) contributes to the obesity of $s / s$ animals. Hence, non-STAT3 LRb signals are critical regulators of NPY expression in the LRb/NPY neuron. Additionally, STAT3 is not likely to be involved in the regulation of membrane potential in ARC neurons, since leptin-regulated membrane potential is too rapid to be mediated by the transcriptional action of STAT3 [29, 69].

Clearly, LRb $\rightarrow$ STAT3-independent pathways regulate glycemic control, reproduction, growth and NPY levels in response to leptin. It is also important to note, however, that the phenotype of the $s / s$ animals does not suggest the irrelevance of non-STAT3 pathways in energy balance, only that STAT3 signaling is important for the regulation of energy homeostasis. Thus, $\mathrm{Tyr}_{1138} \rightarrow$ STAT3-independent signals mediated by $\mathrm{Tyr}_{985}$ or Jak2 may contribute to energy balance as well as to glycemic control, growth and reproductive function. Indeed, PI 3'-kinase activity as well as STAT3 signaling is required for the regulation of feeding and sympathetic nervous system activity by leptin $[60,61,71,72,74]$. Interestingly, mice mutant for $\mathrm{Tyr}_{985}$ of LRb display no obvious defects in leptin action, suggesting that $\mathrm{Tyr}_{985}$-mediated signals do not mediate important positive leptin signals [M. G. Myers et al., unpublished], implying a crucial role for Jak2-dependent, $\mathrm{LRb}$ tyrosine phosphorylation site-independent signals in leptin action in vivo. We speculate that the Jak2-IRS protein-PI 3'-kinase pathway represents a major STAT3independent mediator of $\mathrm{LRb}$ action. Data from numerous laboratories suggest that PI 3 '-kinase action regulates membrane potential in the LRb/NPY neuron [70, 79]; PI 3'-kinase action might similarly control membrane potential in the LRb/POMC neuron. We cannot rule out the possibility that other uncharacterized signals activated by Jak2 tyrosine phosphorylation sites could control NPY expression and/or membrane potential, however.

\section{Leptin resistance and obesity}

Obesity is a growing health problem in the western world and is a major risk factor for type 2 diabetes and cardiovascular disease [80]. Following the discovery of leptin, it was initially hoped that exogenous leptin therapy might induce satiety and weight loss in humans $[1,2,9,12,16]$. Indeed, as in rodents, leptin administration results in reduced appetite and neuroendocrine normalization in (rare) obese leptin-deficient patients [81-83]. Furthermore, leptin was found to be efficacious for the treatment of the hyperphagia and endocrine abnormalities that result from the reduced leptin levels in rodents and humans with very low body fat content due to a number of lipodystrophic [84-86] and eating disorders [87]. Indeed, leptin therapy appears to ameliorate the reduced energy expen- 
diture and increased hunger associated with weight loss in humans [82, 88-92]. Unfortunately, the scale of the weight loss achieved with leptin therapy in most obese humans was modest compared to the expectations of most observers. While this limited response may result in part from the modest doses of leptin that can be administered to humans (in contrast to obese rodents) due to the induction of a local inflammatory reaction by subcutaneous leptin injection, it is also clear that most obese individuals exhibit elevated circulating levels of leptin as a consequence of their increased fat mass, but do not adequately respond to this elevated leptin with reduced food intake. This under-responsiveness to endogenous and exogenous leptin in most forms of human obesity has given rise to the idea that obesity is associated with or even caused by a state of relative leptin resistance, similar to the insulin resistance of type 2 diabetes.

\section{Leptin resistance - transport defects versus signaling defects}

Some investigators have argued against the validity of the concept of leptin resistance, as the physiologic and evolutionarily selected role of leptin is believed to signal undernutrition at low levels rather than preventing overnutrition at high levels. While the evolutionary basis of this argument appears sound, there are examples in nature of temporary leptin resistance, e.g. in seasonal mammals and during pregnancy conditions where food intake must be increased despite elevated body fat and leptin levels $[93,94]$. Furthermore, the finding that high doses of leptin can somewhat reduce feeding in rodents with dietinduced obesity suggests that increased leptin action can be obtained with superphysiolgic doses of leptin and that leptin action does not reach an upper limit within the physiologic range of concentrations [95]. With regard to the pathology of human obesity the major goal therefore is to understand the mechanism(s) triggering leptin resistance, the nature of the processes and molecules that limit action in hyperleptinemic states, and how to bypass these limitations on leptin action.

The identity of the crucial mediator(s) of leptin resistance still remains unclear, but possibilities that have received a good deal of attention include the failure of circulating leptin to reach its targets in the brain and inhibition of the intracellular LRb signaling cascade. The mechanism(s) by which leptin gains access to the brain is still a matter of debate; some have proposed that the movement of leptin into the brain to regulate energy balance is mediated via a specific transport mechanism across the blood brain barrier (BBB) and/or via the circumventricular organs (CVO) [e.g. the median eminence (ME)]. Leptin is clearly transported across the BBB by a saturable transport system that may be in part mediated by short LR forms [96]. In rats lacking all leptin receptor isoforms, there is a marked decrease in leptin transport rate from the circulation into the brain [97]. Consistently, $d b / d b$ mice that lack only LRb but have intact short LRs show normal leptin transport rates into the brain [98]. Decreased leptin transport across the BBB has also been demonstrated in diet-induced-obese (DIO) rodents - a classical model of obesity and leptin resistance in which rodents are made obese by high fat feeding [99]. Furthermore, although leptin-induced signaling to STAT3 is decreased in response to administration of peripheral leptin in DIO animals, central injection of leptin at least partially restores STAT3 activation [100]. While it is possible that the observed differences in the efficacy of central and peripheral leptin injection in DIO could reflect the difficulty of selecting doses of leptin that are directly comparable via these disparate routes of administration, it is also possible that central injection of leptin effectively bypasses a defect in leptin transport across the BBB in DIO.

Whether or not defective leptin transport across the BBB contributes to leptin resistance, it is clear that the ability of leptin to activate hypothalamic signaling is decreased in DIO. A number of investigators, including us, have thus begun to examine mechanisms of LRb signal attenuation in cultured cells and in vivo. At this juncture, a wealth of data supports roles for two inhibitory molecules in the regulation of $\mathrm{LRb}$ signaling: SOCS3 and the protein tyrosine phosphatase, PTP1B [51, 52, 95, 100-104]. Overexpression of each of these proteins in cultured cells

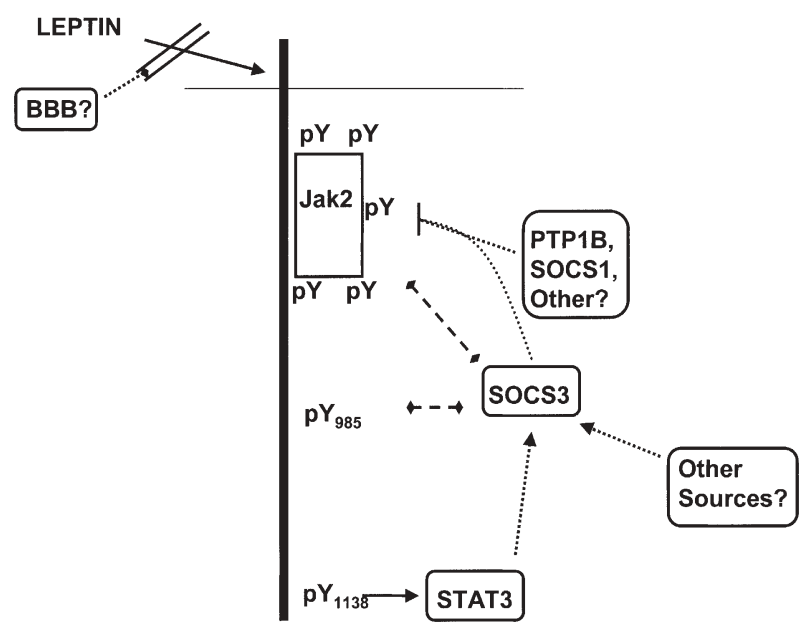

Figure 3. Mechanisms of LRb signal attenuation. A number of pathways limit leptin action in vivo. Leptin is transported across the $\mathrm{BBB}$ to access some regions of the brain, and this may limit the access of leptin to some target cells. Furthermore, STAT3 signaling by $\mathrm{LRb}$ induces the expression of the inhibitory SOCS3, which attenuates $\mathrm{LRb}$ action by binding to $\mathrm{Tyr}_{985}$ and to Jak2. Other factors may also promote the expression of SOCS3. SOCS3 and the tyrosine phosphatase PTP1B have been shown to limit leptin action in vivo, but other proteins, such as SOCS1, may also contribute to LRb signal attenuation. 
attenuates leptin signaling, and there are data from genetically altered mice to suggest roles for these molecules in the inhibition of LRb signaling. Mice null for PTP1B are not only insulin sensitive, as first reported, but are lean and somewhat hypophagic with no noted neuroendocrine abnormalities [101-103], suggesting increased leptin sensitivity may actually underlie the metabolic phenotype of these animals. Indeed, several lines of in vivo data suggest that at least part of the lean phenotype of these animals is secondary to enhanced hypothalamic leptin action. A role for SOCS3 in limiting LRb action in vivo has been implied by the finding of elevated SOCS3 in some rodent models of obesity, as well as the recent demonstration of leanness and leptin sensitivity in mice haploinsufficient for SOCS3 and in mice lacking SOCS3 in the CNS $[51,95,104]$ (complete knockout of SOCS3 is lethal due to the role of SOCS3 in limiting signaling by multiple cytokine receptors) [105-109]. Clearly, these data suggest that PTP1B and SOCS3 are important physiologic determinants of LRb signal strength, although their potential dysregulation in obesity is not known. While no in vivo data are available to examine the potential role of the related SOCS1, expression of SOCS1 in cultured cells also interferes with LRb signaling [104].

While $\mathrm{LRb}$ has not been shown to regulate the expression of PTP1B, the LRb $\rightarrow$ STAT3 pathway stimulates SOCS3 expression $[45,51,52]$, prompting the suggestion that high levels of leptin may induce SOCS3 expression and thus the attenuation of LRb signaling in obesity. Indeed, hypothalamic expression of SOCS3 is elevated in several rodent models of obesity [51], suggesting that some signal related to obesity induces the expression of SOCS3 in leptin-sensitive neurons. The idea that leptin itself would stimulate SOCS3 expression to induce leptin insensitivity in vivo has met with resistance on theoretical grounds: this increase in SOCS3 should inhibit LRb signaling, in turn decreasing the expression of SOCS3. Thus, how could inhibitory levels of SOCS3 be maintained if leptin itself induces them? Certainly, however, leptin does induce the expression of SOCS3 in cultured cells and in vivo, and leptin-mediated induction of SOCS3 does correlate with the attenuation of $\mathrm{LRb}$ signaling in cultured cells $[45,51,52]$. We hypothesize that the function of this $\mathrm{LRb} \rightarrow \mathrm{SOCS} 3$ pathway in vivo could explain the diminishing effectiveness of increasing leptin concentrations in obesity. This hypothesis suggests that at low baseline concentrations of leptin, incremental changes in leptin would be almost fully translated into increased LRb signaling, while at high circulating levels (as in obesity), the increased expression of SOCS3 would mitigate most of the increase in LRb signaling. Indeed, numerous data from cultured cells suggest that chronic high-level LRb activation induces its own feedback inhibition, probably via SOCS3 [45, 51, 52], effectively limiting the efficacy of high concentrations of leptin during chronic exposure.
It is certainly possible that other signals may increase SOCS3 expression of and/or other mediators of leptin resistance in vivo, however; these other potential inducers of SOCS3 expression include inflammatory mediators and cytokines such as IL- 6 and tumor necrosis factor $\alpha$ (TNF $\alpha$ ), fatty acids and other lipids, and activators of counter-regulatory signals such as corticosteroids.

\section{Insights from the anatomic specificity of leptin resistance}

The anatomic distribution of leptin insensitivity was recently investigated in DIO mice by examining the activation of STAT3 signaling by peripheral leptin [110]. Both by immunohistochemistry and in microdissected nuclei from the hypothalamus, it was clear that this leptin signal was primarily attenuated in the ARC, whereas other hypothalamic and extra-hypothalamic sites remained leptin sensitive. In addition, this site-specific resistance correlated with increased expression of SOCS3 in the ARC relative to other hypothalamic nuclei (e.g. the $\mathrm{VMH} / \mathrm{DMH}$ ), suggesting a role for SOCS3 expression in the ARC in the development of leptin resistance. These findings are consistent with previous findings that suggest a selectivity of leptin resistance: Correia et al. [111] showed that obese leptin-resistant $\mathrm{A}^{\mathrm{y}}$ mice appropriately increased their sympathetic nervous system activity in response to exogenously applied leptin, but failed to decrease their body weight or food intake in response to leptin. ARC-restricted leptin resistance in the brain has also been observed in two natural and reversible models of leptin resistance - pregnant rats and seasonal hamsters (which exhibit a natural annual body weight cycle) [93, 94]. In each of these models, increased body fat and food intake are important for survival, and leptin resistance in these models is therefore beneficial. In both cases the $\mathrm{ARC}$ seems to be the major site showing leptin resistance, suggesting the ARC as the most important site in the development of leptin resistance. Furthermore these data suggest that leptin resistance can represent a regulatory rather than a pathological event in response to specific energy needs.

How might the ARC leptin signaling system be singled out for leptin resistance? While the brain is generally protected from circulating factors by the BBB, secretory neurons in the hypothalamus must be in open communication with blood capillaries in order to effect the secretion of their hormones, and this contact with the circulation may also allow these neurons to sense blood-borne factors [112]. Furthermore, the ME, part of the CVO, lacks the typical BBB [113], and the ARC is closely apposed to the ME. Indeed, the ARC of young mice is specifically sensitive to the neurodegenerative effects of peripherally applied monosodium glutamate (MSG), sug- 
gesting that the ARC is accessible to circulating molecules, at least in juveniles [114]. Some authors have suggested that leptin does not pass through the BBB in order to gain access to the basomedial hypothalamus [115] By extension, the finding of selective leptin resistance in the ARC, where the movement of leptin or other mediators across the BBB may not be required in order to access LRb-expressing neurons, suggests that leptin resistance may not be secondary to defective leptin transport. Indeed, it is possible that the limitations of the transport of leptin and/or other stimulators of leptin resistance across the BBB into sites other than the ARC could protect these sites from leptin resistance, while the ARC is continually exposed to them.

\section{Summary}

The function of leptin as we currently understand it is to de-emphasize feeding and permit energy expenditure when body energy stores are replete. We have learned a great deal about the mechanisms of leptin action via $L R b$ signaling and are beginning to understand a variety of neural circuits regulated by leptin. There remain, however, a number of substantial voids in our knowledge regarding $\mathrm{LRb}$ signals that likely control important aspects of mammalian physiology and regarding numerous poorly characterized populations of leptin-regulated neurons in the CNS. Furthermore, although we are beginning to understand some of the mechanisms that limit $\mathrm{LRb}$ action in vivo (e.g. PTP1B, SOCS3), the relevance of these molecules to common obesity is not clear; nor is the function of these molecules and/or the BBB to the development of leptin resistance. The elucidation of these mechanisms over the next few years will hopefully reveal molecular details of the processes that contribute to the development of obesity.

1 Friedman J. M. and Halaas J. L. (1998) Leptin and the regulation of body weight in mammals. Nature 395: 763-770

2 Elmquist J. K., Maratos-Flier E., Saper C. B. and Flier J. S. (1998) Unraveling the central nervous system pathways underlying responses to leptin. Nature Neurosci. 1: 445-449

3 Bates S. H. and Myers M. G. Jr (2003) The role of leptin receptor signaling in feeding and neuroendocrine function. Trends Endocrinol. Metab. 14: 447-452

4 Kennedy G. C. (1953) The role of depot fat in the hypothalamic control of food intake in rats. Proc. R. Soc. 140: 578-592

5 Ahima R. S., Prabakaran D., Mantzoros C. S., Qu D., Lowell B. B., Maratos-Flier E. et al. (1996) Role of leptin in the neuroendocrine response to fasting. Nature 382: 250-252

6 Lord G. M., Matarese G., Howard J. K., Baker R. J., Bloom S. R. and Lechler R. I. (1998) Leptin modulates the T-cell immune response and reverses starvation-induced immunosuppression. Nature 394: 897-901

7 Montague C. T., Farooqi I. S., Whitehead J. P., Soos M. S., Rau H, Wareham N. J. et al. (1997) Congenital leptin deficiency is associated with severe early onset obesity in humans. Nature 387: 903-908

8 Clement K., Vaisse C., Lahlou N., Cabrol S., Pelloux V., Cassuto D. et al. (1998) A mutation in the human leptin receptor gene causes obesity and pituitary dysfunction. Nature 392: 398-401

9 Tartaglia L. A. (1997) The leptin receptor. J. Biol. Chem. 272: 6093-6096

10 Chua S. C. Jr, Koutras I. K., Han L., Liu S. M., Kay J., Young S. J. et al. (1997) Fine structure of the murine leptin receptor gene: splice site suppression is required to form two alternatively spliced transcripts. Genomics 45: 264-270

11 Ge H., Huang L., Pourbahrami T. and Li C. (2002) Generation of soluble leptin receptor by ectodomain shedding of membrane-spanning receptors in vitro and in vivo. J Biol Chem 277: 45898-45903

12 Elmquist J. K., Elias C. F. and Saper C. B. (1999) From lesions to leptin: hypothalamic control of food intake and body weight. Neuron 22: 221-232

13 Elmquist J. K., Bjorbaek C., Ahima R. S., Flier J. S. and Saper C. B. (1998) Distributions of leptin receptor mRNA isoforms in the rat brain. J. Comp. Neurol. 395: 535-547

14 Baskin D. G., Schwartz M. W., Seeley R. J., Woods S. C., Porte D. Jr, Breininger J. F. et al. (1999) Leptin receptor long-form splice-variant protein expression in neuron cell bodies of the brain and co-localization with neuropeptide $\mathrm{Y}$ mRNA in the arcuate nucleus. J. Histochem. Cytochem. 47: 353-362

15 Schwartz M. W., Woods S. C., Porte D. Jr, Seeley R. J. and Baskin D. G. (2000) Central nervous system control of food intake. Nature 404: 661-671

16 Inui A. (1999) Feeding and body-weight regulation by hypothalamic neuropeptides - mediation of the actions of leptin. Trends Neurosci. 22: 62-67

17 Huo L., Munzberg H., Nillni E. A. and Bjorbaek C. (2004) Role of signal transducer and activator of transcription 3 in regulation of hypothalamic trh gene expression by leptin. Endocrinology 145: 2516-2523

18 Elmquist J. K., Ahima R. S., Maratos-Flier E., Flier J. S. and Saper C. B. (1997) Leptin activates neurons in ventrobasal hypothalamus and brainstem. Endocrinology 138: 839-842

19 Liu L., Karkanias G. B., Morales J. C., Hawkins M., Barzilai N., Wang J. et al. (1998) Intracerebroventricular leptin regulates hepatic but not peripheral glucose fluxes. J. Biol. Chem. 273: 31160-31167

20 Kulkarni R. N., Wang Z. L., Wang R. M., Hurley J. D., Smith D. M., Ghatei M. A. et al. (1997) Leptin rapidly suppresses insulin release from insulinoma cells, rat and human islets and, in vivo, in mice. J. Clin. Invest. 100: 2729-2736

21 Burcelin R., Kamohara S., Li J., Tannenbaum G. S., Charron M. J. and Friedman J. M. (1999) Acute intravenuous leptin infusion increases glucose turnover but not skeletal muscle glucose uptake in ob/ob mice. Diabetes 48: 1264-1269

22 Kieffer T. J., Heller R. S., Leech C. A., Holz G. G. and Habener J. F. (1997) Leptin suppression of insulin secretion by the activation of ATP-sensitive $\mathrm{K}^{+}$channels in pancreatic betacells. Diabetes 46: 1087-1093

23 Huszar D., Lynch C. A., Fairchild-Huntress V., Dunmore,J. H., Fang Q., Berkemeier L. R. et al. (1997) Targeted disruption of the melanocortin-4 receptor results in obesity in mice. Cell 88: $131-141$

24 Butler A. A. and Cone R. D. (2002) The melanocortin receptors: lessons from knockout models. Neuropeptides 36: $77-$ 84

25 Marsh D. J., Hollopeter G., Huszar D., Laufer R., Yagaloff K. A., Fisher, S. L. et al. (1999) Response of melanocortin-4 receptor-deficient mice to anorectic and orexigenic peptides. Nat. Genet. 21: 119-122

26 Ste Marie L., Miura G. I., Marsh D. J., Yagaloff K. and Palmiter R. D. (2000) A metabolic defect promotes obesity in 
mice lacking melanocortin-4 receptors. Proc. Natl. Acad. Sci. USA 97: 12339-12344

27 Butler A. A., Kesterson R. A., Khong K., Cullen M. J., Pelleymounter M. A., Dekoning J. et al. (2000) A unique metabolic syndrome causes obesity in the melanocortin-3 receptordeficient mouse. Endocrinology 141: 3518-3521

28 Chen A. S., Marsh D. J., Trumbauer M. E., Frazier E. G., Guan X. M., Yu H. et al. (2000) Inactivation of the mouse melanocortin-3 receptor results in increased fat mass and reduced lean body mass. Nat. Genet. 26: 97-102

29 Cowley M. A., Smart J. L., Rubinstein M., Cerdan M. G., Diano S., Horvath T. L. et al. (2001) Leptin activates anorexigenic POMC neurons through a neural network in the arcuate nucleus. Nature 411: 480-484

30 Wren A. M., Small C. J., Abbott C. R., Dhillo W. S., Seal L. J., Cohen M. A. et al. (2001) Ghrelin causes hyperphagia and obesity in rats. Diabetes 50: 2540-2547

31 Chen H. Y., Trumbauer M. E., Chen A. S., Weingarth D. T., Adams J. R., Frazier E. G. et al. (2004) Orexigenic action of peripheral ghrelin is mediated by neuropeptide $\mathrm{Y}$ and agoutirelated protein. Endocrinology 145: 2607-2612

32 Qian S., Chen H., Weingarth D., Trumbauer M. E., Novi D. E., Guan X. et al. (2002) Neither agouti-related protein nor neuropeptide $\mathrm{Y}$ is critically required for the regulation of energy homeostasis in mice. Mol. Cell. Biol. 22: 5027-5035

33 Erickson J. C., Hollopeter G. and Palmiter R. D. (1996) Attenuation of the obesity syndrome of ob/ob mice by the loss of neuropeptide Y. Science 274: 1704-1707

34 Sindelar D. K., Mystkowski P., Marsh D. J., Palmiter R. D. and Schwartz M. W. (2002) Attenuation of diabetic hyperphagia in neuropeptide Y-deficient mice. Diabetes 51: 778-783

35 MacNeil D. J., Howard A. D., Guan X., Fong T. M., Nargund R. P., Bednarek M. A. et al. (2002) The role of melanocortins in body weight regulation: opportunities for the treatment of obesity. Eur. J. Pharmacol. 450: 93-109

36 Balthasar N., Coppari R., McMinn J., Liu S. M., Lee C. E., Tang V. et al. (2004) Leptin receptor signaling in POMC neurons is required for normal body weight homeostasis. Neuron 42: 983-991

37 Munzberg H., Huo L., Nillni E. A., Hollenberg A. N. and Bjorbaek C. (2003) Role of signal transducer and activator of transcription 3 in regulation of hypothalamic proopiomelanocortin gene expression by leptin. Endocrinology 144: 2121-2131

38 Taga T. and Kishimoto T. (1997) gp130 and the interleukin-6 family of cytokines. Ann. Rev. Immunol. 15: 797-819

39 Ihle J. N. and Kerr I. M. (1995) Jaks and Stats in signaling by the cytokine receptor superfamily. TIG 11: $69-74$

40 Taniguchi T. (1995) Cytokine signaling through nonreceptor protein tyrosine kinases. Science 268: 251-255

41 Kloek C., Haq A. K., Dunn S. L., Lavery H. J., Banks A. S. and Myers M. G. Jr (2002) Regulation of Jak kinases by intracellular leptin receptor sequences. J. Biol. Chem. 277: 4154741555

42 Devos R., Guisez Y., Van der Heyden J., White D. W., Kalai M., Fountoulakis M. et al. (1997) Ligand-independent dimerization of the extracellular domain of the leptin receptor and determination of the stoichiometry of leptin binding. J. Biol. Chem. 272: 18304-18310

43 Couturier C. and Jockers R. (2003) Activation of the leptin receptor by a ligand-induced conformational change of constitutive receptor dimers. J. Biol. Chem. 287: 26604 26611

44 White D. W., Kuropatwinski K. K., Devos R., Baumann H. and Tartaglia, L. A. (1997) Leptin receptor (OB-R) signaling. J. Biol. Chem. 272: 4065-4071

45 Banks A. S., Davis S. M., Bates S. H. and Myers M. G. Jr (2000) Activation of downstream signals by the long form of the leptin receptor. J. Biol. Chem. 275: 14563-14572
46 Bahrenberg G., Behrmann I., Barthel A., Hekerman P., Heinrich P. C., Joost H. G. et al. (2002) Identification of the critical sequence elements in the cytoplasmic domain of leptin receptor isoforms required for janus kinase/signal transducer and activator of transcription activation by receptor heterodimers. Mol. Endocrinol. 16: 859-872

47 Koch C. A., Anderson D. J., Moran M. F., Ellis C. A. and Pawson T. (1991) SH2 and SH3 domains: elements that control interactions of cytoplasmic signaling proteins. Science 252: 668-674

48 Songyang Z., Shoelson S. E., Chaudhuri M., Gish G. D., Pawson T., Haser W. G. et al. (1993) SH2 domains recognize specific phosphopeptide sequences. Cell 72: 767-778

49 Haan S., Hemmann U., Hassiepen U., Schaper F., SchneiderMergener J., Wollmer A. et al. (1999) Characterization and binding specificity of the monomeric STAT3-SH2 domain. J. Biol. Chem. 274: 1342-1348

50 Bjorbaek C., Buchholz R. M., Davis S. M., Bates S. H., Pierroz D. D., Gu H. et al. (2001) Divergent roles of SHP-2 in ERK activation by leptin receptors. J. Biol. Chem. 276: $4747-4755$

51 Bjorbaek C., Elmquist J. K, Frantz J. D., Shoelson S. E. and Flier J. S. (1998) Identification of SOCS-3 as a potential mediator of central leptin resistance. Mol. Cell. 1: 619-625

52 Bjorbaek C., Lavery H. J., Bates S. H., Olson R. K., Davis S. M., Flier J. S. et al. (2000) SOCS3 mediates feedback inhibition of the leptin receptor via Tyr985. J. Biol. Chem. 275: 40649-40657

53 Sasaki A., Yasukawa H., Shouda T., Kitamura T., Dikic I. and Yoshimura A. (2000) CIS3/SOCS3 suppresses erythropoietin signaling by binding the EPO receptor and JAK2. J. Biol. Chem. 275: 29338-29347

54 Sasaki A., Yasukawa H., Suzuki A., Kamizono S., Syoda T., Kinjyo I. et al. (1999) Cytokine-inducible SH2 protein-3 (CIS3/SOCS3) inhibits Janus tyrosine kinase by binding through the N-terminal kinase inhibitory region as well as SH2 domain. Genes Cells 4: 339-351

55 Feng J., Witthuhn B. A., Matsuda T., Kohlhuber F., Kerr I. M. and Ihle J. N. (1997) Activation of Jak2 catalytic activity requires phosphorylation of $\mathrm{Y}^{1007}$ in the kinase activation loop. Mol. Cell. Biol. 17: 2497-2501

56 Carpino N., Kobayashi R., Zang H., Takahashi Y., Jou S. T., Feng J. et al. (2002) Identification, cDNA cloning and targeted deletion of p70, a novel, ubiquitously expressed SH3 domaincontaining protein. Mol. Cell. Biol. 22: 7491-7500

57 Argetsinger L. S., Kouadio J. L., Steen H., Stensballe A., Jensen O. N. and Carter-Su C. (2004) Autophosphorylation of JAK2 on tyrosines 221 and 570 regulates its activity. Mol. Cell. Biol. 24: 4955-4967

58 Feener E. P., Rosario F., Dunn S. L., Stancheva Z. and Myers M. G. Jr (2004) Tyrosine phosphorylation of Jak2 in the JH2 domain inhibits cytokine signaling. Mol. Cell. Biol. 24: 4968-4978

59 Kurzer J. H., Argetsinger L. S., Zhou Y. J., Kouadio J. L., O'Shea J. J. and Carter-Su C. (2004) Tyrosine 813 is a site of JAK2 autophosphorylation critical for activation of JAK2 by SH2-B beta. Mol. Cell. Biol. 24: 4557-4570

60 Niswender K. D., Morton G. J., Stearns W. H., Rhodes C. J., Myers M. G. Jr and Schwartz, M. W. (2001) Intracellular signalling. Key enzyme in leptin-induced anorexia. Nature 413: 794-795

61 Niswender K. D., Morrison C. D., Clegg D. J., Olson R., Baskin D. G., Myers M. G. Jr et al. (2003) Insulin activation of phosphatidylinositol 3-kinase in the hypothalamic arcuate nucleus: a key mediator of insulin-induced anorexia. Diabetes 52: $227-231$

62 Argetsinger L. S., Hsu G. W., Myers,M. G. Jr, Billestrup N., White M. F. and Carter-Su C. (1995) Growth hormone, interferon- $\gamma$ and leukemia inhibitory factor promoted tyrosyl phos- 
phorylation of insulin receptor substrate-1. J. Biol. Chem. 270: $14685-14692$

63 Carvalheira J. B., Ribeiro E. B., Araujo E. P., Guimaraes R. B., Telles M. M., Torsoni M. et al. (2003) Selective impairment of insulin signalling in the hypothalamus of obese Zucker rats. Diabetologia 46: 1629-1640

64 Carvalheira J. B., Siloto R. M., Ignacchitti I., Brenelli S. L., Carvalho C. R., Leite A. et al. (2001) Insulin modulates leptin-induced STAT3 activation in rat hypothalamus. Growth Regul. 500: 119-124

65 Myers M. G. Jr and White M. F. (2002) The molecular basis of insulin action. 4: 712-727

66 Withers D. J., Gutierrez J. S., Towery H., Burks D. J., Ren J. M., Previs S. et al. (1998) Disruption of IRS-2 causes type 2 diabetes in mice. Nature 391: 900-904

67 Burks D. J., de Mora J. F., Schubert M., Withers D. J., Myers M. G. Jr, Towery H. H. et al. (2000) IRS-2 pathways integrate female reproduction and energy homeostasis. Nature 407: 377-382

68 Araki E., Lipes M. A., Patti M. E., Brüning J. C., Haag B. L. III, Johnson R. S. et al. (1994) Alternative pathway of insulin signalling in mice with targeted disruption of the IRS-1 gene. Nature 372: 186-190

69 Spanswick D., Smith M. A., Groppi V. E., Logan S. D. and Ashford M. L. (1997) Leptin inhibits hypothalamic neurons by activation of ATP-sensitive potassium channels. Nature 390: $521-525$

70 Harvey J., McKay N. G., Walker K. S., Van der Kaay J., Downes C. P. and Ashford M. L. (2000) Essential role of phosphoinositide 3-kinase in leptin-induced K(ATP) channel activation in the rat CRI-G1 insulinoma cell line. J. Biol. Chem. 275: 4660-4669

71 Rahmouni K., Haynes W. G., Morgan D. A. and Mark A. L. (2003) Intracellular mechanisms involved in leptin regulation of sympathetic outflow. Hypertension 41: 763-767

72 Bates S. H., Stearns W. H., Schubert M., Tso A. W. K., Wang Y., Banks A. S. et al. (2003) STAT3 signaling is required for leptin regulation of energy balance but not reproduction. Nature 421: 856-859

73 Schweizer U., Gunnersen J., Karch C., Wiese S., Holtmann B., Takeda K. et al. (2002) Conditional gene ablation of Stat3 reveals differential signaling requirements for survival of motoneurons during development and after nerve injury in the adult. J. Cell. Biol. 156: 287-297

74 Bates S. H., Dundon T. A., Seifert M., Carlson M., MaratosFlier E. and Myers M. G. Jr (2004) LRb-STAT3 signaling is required for the neuroendocrine control of energy expenditure by leptin. Diabetes 53: 3067-3073

75 Guo F., Bakal K., Minokoshi Y. and Hollenberg A. N. (2004) Leptin signaling targets the thyrotropin-releasing hormone gene promoter in vivo. Endocrinology 145: 2221-2227

76 Legradi G. and Lechan R. M. (1998) The arcuate nucleus is the major source for neuropeptide Y-innervation of thyrotropin-releasing hormone neurons in the hypothalamic paraventricular nucleus. Endocrinology 139: 3262-3270

77 Fekete C., Legradi G., Mihaly E., Huang Q. H., Tatro J. B., Rand W. M. et al. (2000) alpha-Melanocyte-stimulating hormone is contained in nerve terminals innervating thyrotropin-releasing hormone-synthesizing neurons in the hypothalamic paraventricular nucleus and prevents fasting-induced suppression of prothyrotropin-releasing hormone gene expression. J. Neurosci. 20: $1550-1558$

78 Mihaly E., Fekete C., Tatro J. B., Liposits Z., Stopa E. G. and Lechan R. M. (2000) Hypophysiotropic thyrotropin-releasing hormone-synthesizing neurons in the human hypothalamus are innervated by neuropeptide $\mathrm{Y}$, agouti-related protein, and alpha-melanocyte-stimulating hormone. J. Clin. Endocrinol. Metab 85: 2596-2603

79 Spanswick D., Smith M. A., Groppi V. E., Logan S. D. and Ashford M. (1997) Leptin inhibits hypothalamic neurons by activation of ATP-sensitive potassium channels. Nature 390: $521-525$

80 Roth J. (1998) Diabetes and obesity. Diab. Met. Rev. 13: 1-2

81 Farooqi I. S., Jebb S. A., Langmack G., Lawrence E., Cheetham C. H., Prentice A. M. et al. (1999) Effects of recombinant leptin therapy in a child with congenital leptin deficiency. N. Engl. J. Med. 341: 879-884

82 Fogteloo A. J., Pijl H., Frolich M., McCamish M. and Meinders A. E. (2003) Effects of recombinant human leptin treatment as an adjunct of moderate energy restriction on body weight, resting energy expenditure and energy intake in obese humans. Diabetes Nutr. Metab 16: 109-114

83 Licinio J., Caglayan S., Ozata M., Yildiz B. O., de Miranda P. B., O'Kirwan F. et al. (2004) Phenotypic effects of leptin replacement on morbid obesity, diabetes mellitus, hypogonadism, and behavior in leptin-deficient adults. Proc. Natl. Acad. Sci. USA 101: 4531-4536

84 McDuffie J. R., Riggs P. A., Calis K. A., Freedman,R. J., Ora E. A., Depaoli A. M. et al. (2004) Effects of exogenous leptin on satiety and satiation in patients with lipodystrophy and leptin insufficiency. J. Clin. Endocrinol. Metab. 89: 4258-4263

85 Oral E. A., Simha V., Ruiz E., Andewelt A., Premkumar A., Snell, P. et al. (2002) Leptin-replacement therapy for lipodystrophy. N. Engl. J. Med. 346: 570-578

86 Shimomura I., Hammer R. E., Ikemoto S., Brown M. S. and Goldstein J. L. (1999) Leptin reverses insulin resistance and diabetes mellitus in mice with congenital lipodystrophy [In Process Citation]. Nature 401: 73-76

87 Welt C. K., Chan J. L., Bullen J., Murphy R., Smith P., Depaoli A. M. et al. (2004) Recombinant human leptin in women with hypothalamic amenorrhea. N. Engl. J. Med. 351: 987-997

88 Chan J. L., Heist K., Depaoli A. M., Veldhuis J. D. and Mantzoros C. S. (2003) The role of falling leptin levels in the neuroendocrine and metabolic adaptation to short-term starvation in healthy men. J. Clin. Invest. 111: 1409-1421

89 Fogteloo J., Meinders E., Frolich M., McCamish M. and Pijl H. (2003) The decline in plasma leptin in response to calorie restriction predicts the effects of adjunctive leptin treatment on body weight in humans. Eur. J. Intern. Med. 14: 415-418

90 Hukshorn C. J., Westerterp-Plantenga M. S. and Saris W. H. (2003) Pegylated human recombinant leptin (PEG-OB) causes additional weight loss in severely energy-restricted, overweight men. Am. J. Clin. Nutr. 77: 771-776

91 Rosenbaum M., Murphy E. M., Heymsfield S. B., Matthews D. E. and Leibel R. L. (2002) Low dose leptin administration reverses effects of sustained weight-reduction on energy expenditure and circulating concentrations of thyroid hormones. J. Clin. Endocrinol. Metab. 87: 2391-2394

92 Westerterp-Plantenga M. S., Saris W. H., Hukshorn C. J. and Campfield L. A. (2001) Effects of weekly administration of pegylated recombinant human $\mathrm{OB}$ protein on appetite profile and energy metabolism in obese men. Am. J. Clin. Nutr. 74: 426-434

93 Tups A., Ellis C., Moar K. M., Logie T. J., Adam C. L., Mercer J. G. et al. (2004) Photoperiodic regulation of leptin sensitivity in the Siberian hamster, Phodopus sungorus, is reflected in arcuate nucleus SOCS-3 (suppressor of cytokine signaling) gene expression. Endocrinology 145: 1185-1193

94 Ladyman S. R. and Grattan D. R. (2004) Region-specific reduction in leptin-induced phosphorylation of signal transducer and activator of transcription-3 (STAT3) in the rat hypothalamus is associated with leptin resistance during pregnancy. Endocrinology 145: 3704-3711

95 Howard J. K., Cave B. J., Oksanen L. J., Tzameli I., Bjorbaek C. and Flier J. S. (2004) Enhanced leptin sensitivity and attenuation of diet-induced obesity in mice with haploinsufficiency of Socs3. Nat. Med. 10: 734-738

96 Banks W. A. (2004) The many lives of leptin. Peptides 25: 331-338 
97 Kastin A. J., Pan W., Maness L. M., Koletsky R. J. and Ernsberger P. (1999) Decreased transport of leptin across the blood-brain barrier in rats lacking the short form of the leptin receptor. Peptides 20: 1449-1453

98 Maness L. M., Banks W. A. and Kastin A. J. (2000) Persistence of blood-to-brain transport of leptin in obese leptindeficient and leptin receptor-deficient mice. Brain Res. 873: $165-167$

99 Levin B. E., Dunn-Meynell A. A. and Banks W. A. (2004) Obesity-prone rats have normal blood-brain barrier transport but defective central leptin signaling before obesity onset. Am. J. Physiol Regul. Integr. Comp Physiol 286: R143-R150

100 El Haschimi K., Pierroz D. D., Hileman S. M., Bjorbaek C. and Flier J. S. (2000) Two defects contribute to hypothalamic leptin resistance in mice with diet-induced obesity. J. Clin. Invest 105: 1827-1832

101 Zabolotny J. M., Bence-Hanulec K. K., Stricker-Krongrad A., Haj F., Wang Y., Minokoshi Y. et al. (2002) PTP1B regulates leptin signal transduction in vivo. Dev. Cell 2: 489495

102 Cheng A., Uetani N., Simoncic P. D., Chaubey V. P., Lee-Loy A., McGlade C. J. et al. (2002) Attenuation of leptin action and regulation of obesity by protein tyrosine phosphatase 1B. Dev. Cell 2: 497-503

103 Elchebly M., Payette P., Michaliszyn E., Cromlish W., Collins, S., Loy A. L. et al. (1999) Increased insulin sensitivity and obesity resistance in mice lacking the protein tyrosine phosphatase-1b gene. Science 283: $1544-1548$

104 Bjorbaek C., El Haschimi K., Frantz J. D. and Flier J. S. (1999) The role of SOCS-3 in leptin signaling and leptin resistance. J. Biol. Chem. 274: 30059-30065

105 Mori H., Hanada R., Hanada T., Aki D., Mashima R., Nishinakamura H. et al. (2004) Socs3 deficiency in the brain elevates leptin sensitivity and confers resistance to dietinduced obesity. Nat. Med. 10: 739-743
106 Kimura A., Kinjyo I., Matsumura Y., Mori H., Mashima R., Harada M. et al. (2004) SOCS3 is a physiological negative regulator for granulopoiesis and granulocyte colonystimulating factor receptor signaling. J. Biol Chem. 279: 6905-6910

107 Croker B. A., Krebs D. L., Zhang J. G., Wormald S., Willson T. A., Stanley E. G. et al. (2003) SOCS3 negatively regulates IL-6 signaling in vivo. Nat. Immunol 4: 540-545

108 Takahashi Y., Carpino N., Cross J. C., Torres M., Parganas E. and Ihle J. N. (2003) SOCS3: an essential regulator of LIF receptor signaling in trophoblast giant cell differentiation. EMBO J 22: 372-384

109 Marine J. C., McKay C., Wang D., Topham D. J., Parganas E., Nakajima H. et al. (1999) SOCS3 is essential in the regulation of fetal liver erythropoiesis. Cell 98: 617-627

110 Munzberg H., Flier J. S. and Bjorbaek C. (2004) Region-Specific Leptin Resistance within the Hypothalamus of Diet-Induced - Obese Mice. Endocrinology 145: 4880-4889

111 Correia M. L., Haynes W. G., Rahmouni K., Morgan D. A., Sivitz W. I. and Mark A. L. (2002) The concept of selective leptin resistance: evidence from agouti yellow obese mice. Diabetes 51: 439-442

112 Krisch B. and Leonhardt H. (1978) The functional and structural border of the neurohemal region of the median eminence. Cell Tissue Res. 192: 327-339

113 Johnson A. K. and Gross P. M. (1993) Sensory circumventricular organs and brain homeostatic pathways. FASEB J. 7: 678-686

$114 \mathrm{Hu}$ L., Fernstrom J. D. and Goldsmith P. C. (1998) Exogenous glutamate enhances glutamate receptor subunit expression during selective neuronal injury in the ventral arcuate nucleus of postnatal mice. Neuroendocrinology 68: 77-88

115 Peruzzo B., Pastor F. E., Blazquez J. L., Schobitz K., Pelaez B., Amat P. et al. (2000) A second look at the barriers of the medial basal hypothalamus. Exp. Brain Res. 132: 10-26 